\title{
Connecting Effective Mathematics Teaching Practices and Mathematical Practices
}

\begin{abstract}
Trena L. Wilkerson ${ }^{1, *}$
\author{
${ }^{1}$ Baylor University, Waco, Texas USA \\ ${ }^{1}$ National Council of Teachers of Mathematics, President
}

*Corresponding author. Email: twilkerson@nctm.org

ABSTRACT

Learning during the pandemic presents a major challenge for mathematics teachers. In this condition, Teacher must examine effective mathematical teaching practices that support each and every student to develop a deep understanding of mathematics; and developing a positive mathematical identity and strong sense of mathematical agency. This paper discusses how do the eight effective mathematics teaching practices support key mathematical practices essential for students to develop to be successful in mathematics. It has been important to support both preservice and inservice teachers in implementing effective teaching practices by providing opportunities for collaboration and planning, resources for teaching and learning mathematics in new settings, professional development on use of new technologies, ways of addressing effective practices in varied environments, and support in identifying mathematical tasks that would support student development of essential mathematical practices and ensure equitable access to high quality learning opportunities.
\end{abstract}

Keywords: Effective Mathematics Teaching, Mathematical Practices

\section{INTRODUCTION}

Across the globe. It is important for all associated with mathematics education to have critical conversations around these areas and then identify potential actions to move the field forward. In 2020 The National Council of Teachers of Mathematics'(NCTM) expanded its Catalyzing Change initiative to early childhood, elementary, and middle school mathematics with Catalyzing Change in Middle School Mathematics: Initiating Critical Conversations along with Catalyzing Change in Early Childhood and Elementary School Mathematics: Initiating Critical Conversations. These documents bridge the conversation begun with the 2018 Catalyzing Change in High School: Initiating Critical Conversations identifying and addressing critical challenges in PK-12 school mathematics to ensure that each and every student develops critical mathematical practices through addressing essential mathematical content to engage successfully in school mathematics and be prepared for the future. Catalyzing Change offers four key recommendations: 1) Broaden the Purposes of Learning Mathematics, 2) Create Equitable Structures in Mathematics, 3) Implement Equitable Mathematics Instruction, and 4) Develop Deep Mathematical
Understanding. While all four recommendations are critical, the primary focus of this paper will be on implementing equitable mathematics instruction, particularly in our current situation of teaching and learning mathematics during the current COVID-19 era in an effort to examine what we have learned to improve mathematical understanding for the future through effective teaching practices.

\section{EFFECTIVE MATHEMATICS TEACHING PRACTICES}

Pandemic conditions is the time to examine effective mathematical teaching practices that support each and every student to develop a deep understanding of mathematics; and developing a positive mathematical identity and strong sense of mathematical agency. In 2014 in Principles to Actions: Ensuring Mathematical Success for All, NCTM identified the following eight effective mathematics teaching practices:

a. Establish mathematics goals to focus learning

b. Implement tasks that promote reasoning and problem solving

c. Use and connect mathematical representations 
d. Facilitate meaningful mathematical discourse

e. Pose purposeful questions

f. Build procedural fluency from conceptual understanding

g. Support productive struggle in learning mathematics, and

h. Elicit and use evidence of student thinking. [1]

How do the eight effective mathematics teaching practices support key mathematical practices essential for students to develop to be successful in mathematics? Examples key mathematical practices for students include reasoning and critiquing the reasoning of others, communicating mathematically, modeling with mathematics, attending to precision, problem solving, persevering in problem solving, cultivating strategic competency and developing productive dispositions [2][3][4]. We should consider important questions such as, What are ways we can effectively support preservice and inservice teachers to implement effective teaching practices? What do or could these practices look like in diverse settings with diverse students to ensure equitable access for each and every student? and What are appropriate ways to study these areas to add to our understanding in mathematics education?

\section{THE WAYS TO IMPLEMENT EFFECTIVE TEACHING PRACTICES}

In June 2020 NCTM joined with the NCSM: Leaders of Mathematics Education organization to consider how to support teachers, schools, administrators, families, and others to address the challenges of teaching and learning mathematics in the midst of COVID-19. NCTM's mission statement (https://www.nctm.org/About/) advocates for high quality mathematics teaching and learning for each and every student, while NCSM: Leaders of Mathematics Education's mission statement (https://www.mathedleadership.org/ncsm-mission-andvision/) revolves around equipping and empowering a diverse education community to engage in leadership that supports, sustains, and inspires this high-quality mathematics teaching and learning. The document, Moving Forward: Mathematics Learning in the Era of COVID-19 (https://www.nctm.org/movingforward/), outlined considerations, questions, challenges, and potential solution processes to aid in addressing the challenges caused by the COVID-19 pandemic. It addressed structural considerations, teaching practices, and advocacy efforts. In particular it underscored the need for moving forward with the use of equitable and effective mathematics teaching practices advocated by NCTM's Principles to Action (2014) mentioned previously. What we have found is that it was important to examine what this looked like in on-line, remote, or hybrid-models and then also in social distancing models necessary when meeting in person in classrooms.

Teachers and mathematics instructional leaders have worked collaboratively to develop a shared sense of essential mathematical content, how to use formative assessments to gather evidence of student learning providing feedback to students and utilizing it to facilitate instructional decisions. Through this they examined and implemented myriad of ways to continue to focus on effective teaching strategies that supported student learning in this new situation. It has been important to support both preservice and inservice teachers in implementing effective teaching practices by providing opportunities for collaboration and planning, resources for teaching and learning mathematics in new settings, professional development on use of new technologies, ways of addressing effective practices in varied environments, and support in identifying mathematical tasks that would support student development of essential mathematical practices and ensure equitable access to high quality learning opportunities. These have come in the form of allocation of planning time; additional within and across grade level planning opportunities; professional development to target instructional strategies, communication with families, and use of technology; and flexible teaching schedules.

NCTM's Teaching Principle [4] notes that "Effective mathematics teaching requires understanding what students know and need to learn and then challenging and supporting them to learn it well" and includes having strong knowledge of mathematics coupled with the ability to select and use effective teaching strategies in order to create an engaging learning environment. Further "effective teaching is the nonnegotiable core that ensures that all students learn mathematics at high levels and that such teaching requires a range of actions at the state or provincial, district, school, and classroom levels" [5]. In 2018 a group of mathematics educators gathered in Costa Rica at the International Consortium in Research in Science and Mathematics Education (ICRSME) conference and discussed what it means to teach mathematics effectively. They were asked to consider in what ways the mathematical teaching practices were viewed as important or useful to them in their work with inservice and preservice teachers. They shared areas related to professional development, teacher education studies, and research. To correlate with the eight effective mathematics teaching practices, they noted things such as

a. Establishing mathematics goals to focus learning using learning progression activities and readings and engaging teachers in focused activities on monitoring and assessing student thinking;

b. Implement tasks that promote reasoning and problem solving by engaging in discussing tasks to promote mathematical reasoning, having learners explain verbally their mathematical thinking; 
c. Using and connecting mathematical representations by having teachers both engage in use of multiple representations in problem solving and also examining research and conducting research related to multiple representations;

d. Facilitating meaningful mathematical discourse by having teacher present problem solving tasks and problems, support teachers in understanding how to assist their students in what it means to communicate understanding verbally, and provided opportunities for teachers to to use technology, manipulatives, and various strategies to support mathematical discourse;

e. Pose purposeful questions by having teachers practice writing and revising questions, model use of questions in classroom activities, and include purposeful questions in lesson plans requiring different types of questions;

f. Build procedural fluency from conceptual understanding by engaging teachers in work on building fluency in both areas;

g. Support productive struggle in learning mathematics through methods courses and professional development to help teachers understand the role of norms to support productive struggle and have experiences in differentiation between productive and unproductive struggle; and

h. Elicit and use evidence of student thinking through modeling effective discourse and processes and engaging teachers in presenting mathematical ideas and analyzing argumentation practices. [5]

This suggests that the eight effective mathematical teaching practices are inextricably linked to the mathematical practices and process we want for our students; that is, the practices and process that are essential for our students to be successful in learning mathematics, to develop as thinkers and doers of mathematics, to understand and critique their world, and to support their entry into college, careers, and professions for the future. This focus on the development of mathematical practices will ensure that students have opportunities to develop a deep mathematical understanding as recommended by NCTM's Catalyzing Change series [6][7][8]. "A mathematics teacher who plans at the outset with the proficiencies, practices, and processes in mind has the mindset to engage each and every student as active participants in their and their peers' mathematics learning"[7]. Thus, we must continue to pursue, examine, study, and support teachers in the connection of effective mathematics teaching practices and mathematical practices for learners in today's context as well as into the future.

\section{CONCLUSION}

While individuals and teams are beginning to study the impact of our current teaching and learning situation in mathematics to see its impact, it is essential that we work together not only in our own locations but globally so that together we add to the body of knowledge on the teaching and learning of mathematics. What have we learned and what can we learn to support teacher growth and development around effective instruction that will move us forward in how effective mathematical teaching practices impact student learning, empower students mathematically and support their development of essential mathematical practices in our current situation and beyond? This is an essential question to pursue.

\section{REFERENCES}

[1] National Council of Teachers of Mathematics. (2014). Principles to Actions: Ensuring Mathematical Success for All. Reston, VA: NCTM

[2] National Governors Association Center for Best Practices (NGA Center) and Council of Chief State School Officers (CCSSO). (2010). Common Core State Standards for Mathematics. Common Core State Standards (College- and Career-Readiness Standards and K-12 Standards in English Language Arts and Math). Washington, D.C.: NGA Center and CCSSO. http://www.corestandards.org

[3] National Research Council (NRC). (2001). Adding it Up: Helping Children Learn Mathematics. Washington, D.C.: National Academies Press.

[4] National Council of Teachers of Mathematics. 2000. Principles and Standards for School Mathematics. Reston, VA: NCTM

[5] Wilkerson, T. (2020). Examining and exploring effective mathematics teaching practices through a global perspective. In Bloom, M.B. \& Quebec Fuentes, S. \& (Eds.), Advancing Science and Mathematics Education for a Sustainable Future. Dallas/Fort Worth, TX: International Consortium for Research in Science and Mathematics XV Consultation

[6] National Council of Teachers of Mathematics. (2020a). Catalyzing Change in Early Childhood and Elementary Mathematics: Initiating Critical Conversations. Reston, VA: NCTM.

[7] National Council of Teachers of Mathematics. (2020b). Catalyzing Change in Middle School Mathematics: Initiating Critical Conversations. Reston, VA: NCTM

[8] National Council of Teachers of Mathematics. (2020c). Catalyzing Change in High School Mathematics: Initiating Critical Conversations. Reston, VA: NCTM 